\title{
Estimation of water use of Pinus tabulaeformis Carr. in Loess Plateau of Northwest China
}

\author{
Shengqi Jian, Zening Wu, Caihong $\mathrm{Hu}^{*}$ \\ College of Water Conservancy \& Environmental, Zhengzhou University, Science road 100, Zhengzhou, China. \\ * Corresponding author. E-mail: jiansq@zzu.edu.cn
}

\begin{abstract}
Tree transpiration plays a determining role in the water balance of forest stands and in seepage water yields from forested catchments, especially in arid and semiarid regions where climatic conditions are dry with severe water shortage, forestry development is limited by water availability. To clarify the response of water use to climatic conditions, sap flow was monitored by heat pulse velocity method from May to September, 2014, in a 40-year-old Pinus tabulaeformis Carr. plantation forest stands in the semiarid Loess Plateau region of Northwest China. We extrapolated the measurements of water use by individual plants to determine the area-averaged transpiration of the woodlands. The method used for the extrapolation assumes that the transpiration of a tree was proportional to its sapwood area. Stand transpiration was mainly controlled by photosynthetically active radiation and vapor pressure deficit, whereas soil moisture had more influence on monthly change in stand transpiration. The mean sap flow rates for individual $P$. tabulaeformis trees ranged from 9 to $54 \mathrm{~L} \mathrm{~d}^{-1}$. During the study period, the mean daily stand transpiration was $1.9 \mathrm{~mm} \mathrm{day}^{-1}$ (maximum 2.9 and minimum $0.8 \mathrm{~mm} \mathrm{day}^{-1}$ ) and total stand transpiration from May to September was $294.1 \mathrm{~mm}$, representing $76 \%$ of the incoming precipitation over this period. Similar results were found when comparing transpiration estimated with sap flow measurements to the Penman-Monteith method (relative error: 16\%), indicating that the scaling procedure can be used to provide reliable estimates of stand transpiration. These results suggested that $P$. tabulaeformis is highly effective at utilizing scarce water resources in semiarid environments.
\end{abstract}

Keywords: Sap flow; Transpiration; Scaling up; Pinus tabulaeformis; Loess Plateau.

\section{INTRODUCTION}

Land degradation is one of the most serious ecological problems in the world and is concerned by most countries (Liu et al., 2010; Moran et al., 2009). Desertification is a type of land degradation, which occurred in arid, semi-arid and part of semi-humid areas (Huang et al., 2011). It is induced by the uncoordination between population and land development, which results in soil erosion by water and wind (Duniway et al., 2010; Zuo, 2014). The vegetation restoration using woody species has been encouraged worldwide for gaining the multiple benefits (Malagnoux, 2007) such as soil erosion control (Huang et al., 2011), sediment reduction (Moran et al., 2009), hydrological regime regulation (Yaseef et al., 2009) and carbon sequestration (Zhao et al., 2011). However, woody species can consume more water by evapotranspiration than other vegetation types, such as natural grassland (Cao et al., 2009). Soils can also strongly dry out in both deeper and shallow soils after applying vegetation restoration (e.g., Cao et al., 2011; Wang et al., 2010; Yaseef et al., 2009). More extreme soil desiccation due to the initially promoted afforestation has led to negative impacts such as decreasing restoration effort (Liu et al., 2010; RodríguezCaballero et al., 2012; Wang et al., 2011), vegetation deterioration and difficulties in renewal and reforestation (Chen et al., 2008), unstable agriculture crop production (Wang et al., 2008), and decreasing ecosystem services (Chazdon, 2008; Liu et al., 2008).

To control the serious soil erosion and restore the degraded ecosystems of the Loess Plateau, large scale vegetation restoration programs have been implemented by the government since the 1950s (Fu et al., 2012; Issa et al., 2011). Fast-growing trees with wood of practical utility were selected historically in the vegetation restoration practice of the region. Pinus tabulaeformis Carr. have been regarded as a prominent reforestation species because of its advantages of drought tolerance, fast growth, and wood utilization (Chen et al., 2008). However, there is a concern about the sustainability of these plantations with regard to their potentially high water consumption and a shortage of water resources in the region. Du et al. (2011) vapor pressure deficit, solar radiation and soil moisture had varying influences on sap flux density in Robinia pseudoacacia, Quercus liaotungensis and Armeniaca sibirica, the sap flow of these species was not very sensitive to changes in soil water conditions. The results suggested that typical indigenous species can manage the water consumption conservatively under both drought and wet conditions. Zhang et al. (2015) used Graniertype thermal dissipation probes in a black locust (Robinia pseudoacacia) plantation and up scaled stand transpiration from individual measurements of stem sap flow. they found that although the stand transpiration is controlled by multiple factors, those contributing to a significant difference vary with time scales. Some factors (e.g. soil moisture) may only be detected upon long-term observations. Similarly, Jiao et al. (2016) suggested that the black locust plantation has adapted to local soil water condition by reducing transpiration, and the major water loss from the plantation was not transpiration. There are no studies reporting stand-scale water use for $P$. tabulaeformis. There is thus an urgent need to quantitatively investigate the water use of these plantations for comprehensive understanding of their ecological properties and for water resource management on the region (Derak and Cortina, 2014; Zhang et al., 2009).

Plant water use can be quantified by several methods, for example the lysimeter method, the large-tree photometer method, the ventilated chamber method, the chemical tracer method, the isotopes tracer method, and thermally based sap-flow methods (Jiao et al., 2011). Among these methods, the sap flow methods make it feasible to estimate plant water use in situ with relatively high temporal resolution and very little disturbance to 
the site. Moreover, the sap flow technique is the only method for investigating forest water use in some conditions, for example in forests on steep slopes or in very small forest stands. Four sap flow methods are currently available for quantification of plant water use in the field, including heat-pulse (Cortina et al., 2011), heat balance (Wang et al., 2013), thermal dissipation probe (TDP) (Granier, 1987) methods and heat field deformation (Han et al., 2012). All four sap flow methods are based on using the thermal dissipation properties of the water flow through the plant stem to estimate sap flux density. The TDP method, which was originally developed by Granier (1987), is now widely used in many studies of tree water use owing to the advantages of easy installation, simple sensor outputs recording, simple sap flow calculations, high accuracy and reliability, and relatively low cost. In homogeneous forests, estimates of water use by the TDP method agree well with estimates obtained by use of other sap flow methods or micrometeorological methods (Xiao et al., 2011). The TDP method is a reliable approach to measure forest tree water use, but which often influenced by environment factors; so it was necessary to investigate how sap flow varies with environmental factors, which would improve our general understanding of the water balance analysis for revegetation activities in the Loess Plateau, and provide a practical water management measure in such areas.

In current study, the TDP method was used to estimate water use of middle-aged $P$. tabulaeformis plantation in the semiarid region of Loess Plateau, China. We hypothesized that the TDP method would measure forest tree water use accurately. The main objective of the study was to estimate the stand-scale transpiration of plantations in the region. Additionally, for characterizing the stand-scale transpiration at this site, the among-tree variation and diurnal and seasonal patterns of the transpiration were analyzed for the growing season. The study would enrich the database to assess forest stand water balance and further provide valuable information for forest management in the region.

\section{MATERIALS AND METHODS Study area description}

The study was conducted in the Anjiapo catchment, Dingxi County $\left(35^{\circ} 35^{\prime} \mathrm{N}, 104^{\circ} 39^{\prime} \mathrm{E}\right)$ of Gansu province in western Chinese Loess Plateau (Fig.1). The annual precipitation (from 1956 to 2010) is $421 \mathrm{~mm}$ with great seasonal variations. Over

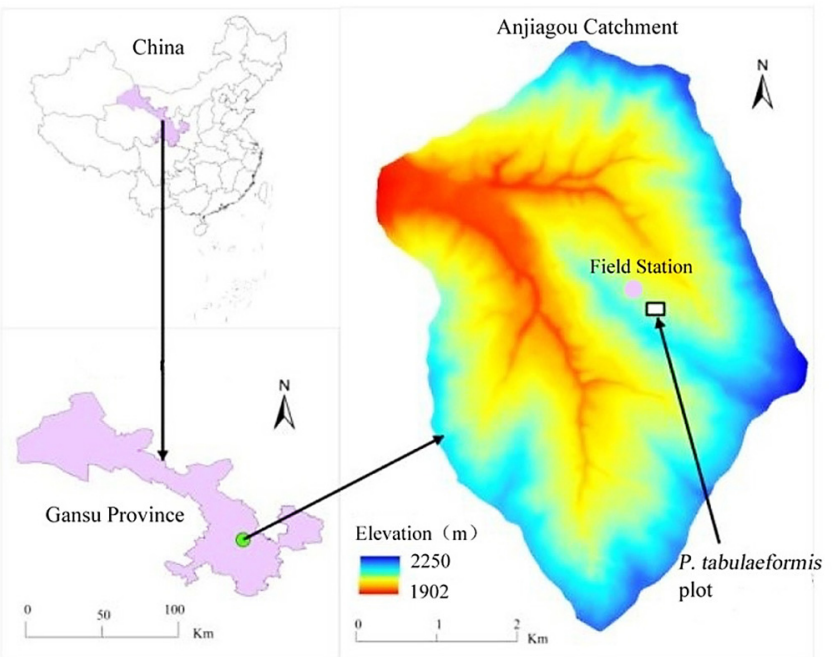

Fig. 1. Location of Anjiagou Catchment and the P. tabulaeformis plantation plot.
$60 \%$ of the precipitation falls between July and September and over $50 \%$ occurs in form of storms. According to more than 50 years (1954-2004) of monitored data, the precipitation showed a decreased trend while the temperature continued to increase during the past decades, which means that the local climate has become drier and warmer. The mean annual pan evaporation is about $1515 \mathrm{~mm}$, the annual mean temperature is $8.5^{\circ} \mathrm{C}$, solar radiation is $932.6 \mathrm{MJ} \mathrm{m}^{-2}$ pear year, and the frost free period is 160 days (Bai and Wang, 2011; Zhang et al., 2010). The average depth to water table is over $50 \mathrm{~m}$ and the typical loess soil has a uniform texture and moderate permeability $\left(0.1-1.2 \mathrm{~cm} \mathrm{~min}^{-1}\right)$ (Ma et al., 2012). Soil bulk density ranged from $1.03 \mathrm{~g} \mathrm{~cm}^{-3}$ to $1.51 \mathrm{~g} \mathrm{~cm}^{-3}$, water content at field capacity ranged from $15 \%$ to $23 \%$ (mass percentage) and at wilting moisture content is $5 \%$ (mass percentage) (Han et al., 2012; Zhang et al., 2010). Silt, clay, and sand content is $75.59 \%, 9.17 \%$ and $15.24 \%$, respectively.

\section{Sap flow measurements}

The experiments were conducted in $P$. tabulaeformis plantation from May to September 2014. Three representative P. tabulaeformis experimental plots of $10 \mathrm{~m} \times 10 \mathrm{~m}$ size were selected randomly on the south-facing slope of the Dianganliang Ridge in the Anjiapo catchment, for measurements of vegetation growth and sap flow. The $L A I$ of the trees in the three plots was $2.65 \pm 0.31$ (mean $\pm \mathrm{SD}$ ), tree height was $10.15 \pm 3.64 \mathrm{~m}$ (mean $\pm \mathrm{SD}$ ), and diameter at breast height $(\mathrm{DBH})$ was $20.3 \pm 3.7$ $\mathrm{cm}$ (mean $\pm \mathrm{SD})$. The root distribution of $P$. tabulaeformis was shallow (Jian et al., 2015), more than $90 \%$ of the roots was concentrated in the $0-100 \mathrm{~cm}$ soil depth.

We used heat pulse meters (SF-L, Greenspan Technology Pty Ltd, Germany) to measure sap flow of P. tabulaeformis. A total of $18 P$. tabulaeformis individuals, out of the three plots were selected ( 6 from each plot) representing a range of properties (Table 1; Fig. 2). The heat pulse velocity probes were installed in the tree stems at $130 \mathrm{~cm}$ above the soil surface, and implanted $20 \mathrm{~mm}$ deep into the xylem of each tree.

The wound diameter was $2 \mathrm{~mm}$. Before insertion, each probe was coated with silicone gel to ensure good thermal contact between probe elements and sapwood. After insertion, the exposed cambium was covered with silicon gel to reduce evaporation, and then covered again with aluminum foil to minimize effects of ambient air temperature fluctuations and solar radiation (Swanson and Whitfield, 1981). The CR1000 data logger (Campbell Scientific, Logan, UT, USA) was used to record sap flux density every 10 minutes. Sap flow velocity $\left(V_{s}, \mathrm{~mm} \mathrm{~h}^{-1}\right)$ was calculated following the method of Edwards and Booker (1984):

$V_{s}=V_{h}^{\prime}\left(0.505 F_{m}+F_{i}\right)$

where, $V_{h}^{\prime}\left(\mathrm{mm} \mathrm{h}^{-1}\right)$ is the heat pulse velocity, $F_{m}$ is the volume fraction of the woody material, and $F_{i}$ is the volume fraction of water. The calculation of $F_{m}$ and $F_{i}$ for each tree required the following inputs: fresh weight $\left(W_{f}, \mathrm{~kg}\right)$, oven-dried weight $\left(W_{d}\right.$, $\mathrm{kg}$ ), and weight of water in the same volume as the sapwood sample $\left(W_{i}, \mathrm{~kg}\right)$. On this basis, $F_{m}$ is:

$$
F_{m}=\frac{W_{d}}{1620 W_{i}}
$$

and $F_{i}$ is: $\quad F_{i}=\frac{W_{f}-W_{d}}{W_{i}}$ 
Table 1. Tree height $(\mathrm{TH})$, sapwood area (SA), and diameter at breast height (DBH) of each individual tree with sap flow measurements at three plots.

\begin{tabular}{|c|c|c|c|c|c|c|c|c|c|}
\hline \multirow{2}{*}{ No. } & \multicolumn{3}{|l|}{ Plot1 } & \multicolumn{3}{|l|}{ Plot2 } & \multicolumn{3}{|l|}{ Plot3 } \\
\hline & $\mathrm{TH}(\mathrm{m})$ & $\mathrm{DBH}(\mathrm{cm})$ & $\mathrm{SA}\left(\mathrm{cm}^{2}\right)$ & $\mathrm{TH}(\mathrm{m})$ & $\mathrm{DBH}(\mathrm{cm})$ & $\mathrm{SA}\left(\mathrm{cm}^{2}\right)$ & $\mathrm{TH}(\mathrm{m})$ & $\mathrm{DBH}(\mathrm{cm})$ & $\mathrm{SA}\left(\mathrm{cm}^{2}\right)$ \\
\hline 1 & 9.68 & 19.1 & 2.58 & 10.25 & 19.2 & 3.21 & 13.65 & 19.5 & 3.11 \\
\hline 2 & 13.21 & 21.1 & 3.11 & 11.26 & 20.3 & 3.34 & 12.68 & 20.4 & 3.52 \\
\hline 4 & 11.52 & 20.6 & 3.02 & 8.64 & 17.5 & 2.55 & 10.62 & 18.6 & 2.94 \\
\hline 5 & 8.83 & 20.3 & 2.84 & 9.52 & 18.7 & 3.05 & 9.57 & 17.9 & 2.73 \\
\hline 6 & 7.51 & 18.7 & 2.51 & 7.68 & 19.6 & 3.09 & 9.77 & 17.1 & 2.66 \\
\hline$A_{c}$ & -- & -- & 54.13 & -- & -- & 59.57 & -- & -- & 57.29 \\
\hline
\end{tabular}

Note: There were 20 trees in plot 1 and plot 2, respectively, 19 trees in plot 3 . The total sapwood area in each plot $\left(A_{c}\right)$ was calculated based on Fig. 2 .

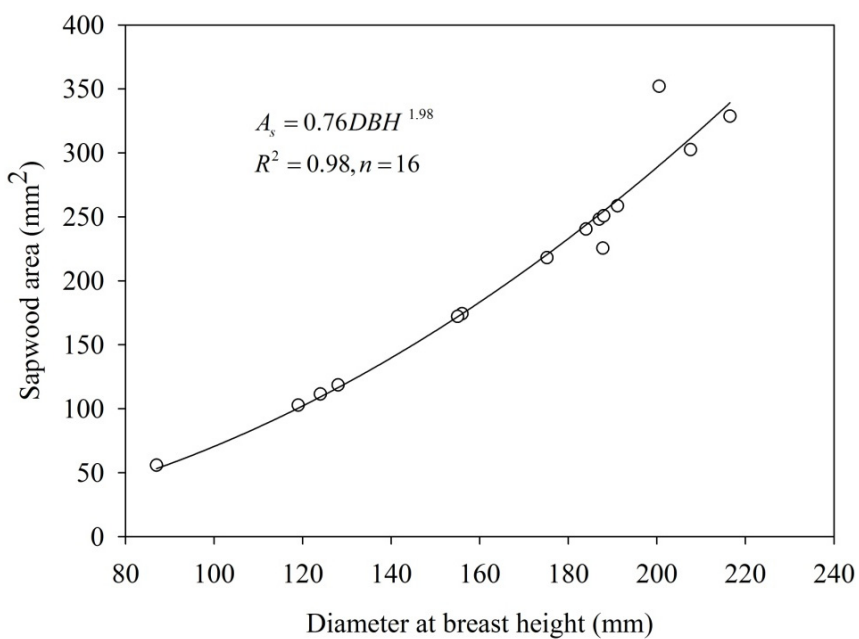

Fig. 2. The relationships between sapwood and diameter at breast height.

Sapwood sample was selected with five replications. Firstly, their $W_{f}$ was measured. Secondly, sapwood sample was completely immersed into the distilled water. The distilled water was placed in the metering cylinder. The volume change between before immersed and after immersed were compared, and weight of water in the same volume as the sapwood sample, $W_{i}$ was calculated. Finally, sapwood sample was put in the oven and oven-dried it at $80^{\circ} \mathrm{C}$. Then, after $W_{d}$ was determined, $F_{m}$ and $F_{i}$ were calculated. The averages of $F_{m}$ and $F_{i}$ were used to calculate the $V_{s}$ value. The average values of $F_{m}$ and $F_{i}$ were 0.36 and 0.27 , respectively.

Sap flux $\left(S F, \mathrm{~mm}^{3} \mathrm{~h}^{-1}\right)$ is a function of the velocity of sap flow and the area of conducting wood in which the flow occurs:

$S F=V_{s} A_{c}$

where, $A_{c}\left(\mathrm{~mm}^{2}\right)$ is the area of conducting wood.

Daily cumulative sap flow $\left(S F_{c}, \mathrm{~kg} \mathrm{~d}^{-1}\right)$ in sample trees is essentially equal to the daily sums of transpiration for time periods of one day or longer (Čermák et al., 1995). The dynamic response of the measured sap flow to atmospheric forcing occurred virtually immediately. $S F$ was so tightly coupled to the climatic variables that no time shift was needed to fit a simple static microclimatic model to estimate SF (Blackman and Brodribb, 2011).

Tree transpiration $\left(E_{t}, \mathrm{~kg} \mathrm{~m}^{-2} \mathrm{~d}^{-1}\right)$ was expressed as sap flux on the sapwood area at breast height. In order to calculate sap flux $\left(\mathrm{kg} \mathrm{m}^{-2} \mathrm{~h}^{-1}\right)$ for a given tree, $V_{s}$ (Eq. (1)) was divided by the sap wood area of the tree.

Tree-level sap flow was scaled up to the stand level to calculate stand transpiration $\left(E_{s}, \mathrm{~kg} \mathrm{~d}^{-1}\right)$ based on the trees' estimated sapwood areas. We assumed that the water velocity on a given date was the same per unit of sap flow area (i.e., that velocity did not vary within the sapwood in different trees). Therefore, $E_{s}$ was estimated as:

$$
E_{s}=\sum_{i=1}^{n} E_{s i}=\sum_{i=1}^{n} E_{s t i} \frac{A_{T, s w}}{A_{S, s w}}
$$

where, $E_{s i}\left(\mathrm{~kg} \mathrm{~d}^{-1}\right)$ represents the stand transpiration on day $i$, $E_{\text {sti }}\left(\mathrm{kg} \mathrm{d}^{-1}\right)$ represents the sample tree transpiration on day $i$, $A_{T, s w}\left(\mathrm{~mm}^{2}\right)$ is the total stand's sapwood area, and $A_{s, s w}\left(\mathrm{~mm}^{2}\right)$ is a given sample tree's sapwood area.

Canopy transpiration $\left(E_{c}, \mathrm{~mm} \mathrm{~d}^{-1}\right)$ equals $E_{c}$ weighted by the canopy's projected area. Crown projection areas were estimated from below the crown by sighting vertically at various positions around each tree. We measured the distances between the stem and the outermost projected point of the branches in all directions, and then drew the proportional lengths on standard crosssection paper to estimate the crowns' projection areas.

\section{Meteorological measurements}

An automated weather station (AG1000, Onset Computer Corporation, Pocasset, MA, USA) was situated located about $100 \mathrm{~m}$ away on an open field from the experimental field. The meteorological variables were wind speed and direction, air temperature, relative humidity, net and photosynthetically active radiation, soil temperature, soil moisture, soil heat flux, rainfall, and atmospheric pressure. The sensors were installed at two levels in 2 and $3 \mathrm{~m}$ above the ground. Rainfall was measured with a tipping-bucket rain gauge, $1.5 \mathrm{~m}$ above ground (model TE525, metric; Texas Electronics, Dallas, TX). Volumetric soil moisture was measured by means of TDR probes (Decagon Devices, Pullman, WA, USA), installed at four soil depths $(10,20,30$ and $40 \mathrm{~cm})$. Also, soil water content was measured every 30 days by means of oven-drying to validate the soil moisture data provided by the probes during the study period. Soil bulk density was measured at each soil layer where the soil moisture probes were installed by cutting ring method.

The meteorological data were measured at a frequency of 10 $\mathrm{Hz}$, recorded every 5 min using a CR1000 data logger (Campbell Scientific Inc., Logan, UT), then stored as 30-min mean values, whereas rainfall and wind data were stored as the 10min mean values. We averaged the measured data in one day as the daily vapor pressure deficit and daily photosynthetically active radiation.

We used data from the weather station to estimate evapotranspiration with the Penman-Monteith equation (Allen et al., 1998):

$$
E T_{0}=\frac{0.408 \Delta\left(R_{n}-G\right)+\gamma(900 / T+273) u_{2}\left(e_{2}-e_{a}\right)}{\Delta+\lambda\left(1+0.34 u_{2}\right)}
$$

where $R_{n}$ is net radiation at the plant surface $\left(\mathrm{MJ} \mathrm{m}^{-2} \mathrm{~d}^{-1}\right), G$ is 
soil heat flux $\left(\mathrm{MJ} \mathrm{m}^{-2} \mathrm{~d}^{-1}\right), \Delta$ is vapor pressure curve slope $(\mathrm{kPa}$ $\left.{ }^{\circ} \mathrm{C}^{-1}\right), \quad \gamma$ is psychrometric constant $\left(\mathrm{kPa}{ }^{\circ} \mathrm{C}^{-1}\right), T$ is mean air temperature $\left({ }^{\circ} \mathrm{C}\right), u_{2}$ is wind speed at $2 \mathrm{~m}$ height $\left(\mathrm{m} \mathrm{s}^{-1}\right)$, and $e_{s}-e_{a}$ is saturation vapor pressure deficit $(\mathrm{kPa})$.

The plant evapotranspiration $\left(E T_{c}\right)$ is given by:

$$
E T_{c}=k_{c} \cdot E T_{0}
$$

where $k_{c}$ is the crop coefficient. $P$. tabulaeformis is mature in our experiment, so in this paper, $k_{c}=0.69$ for $P$. tabulaeformis (Wang et al., 2009).

$$
T_{c}=E T_{c}-E_{p}
$$

where $T_{c}$ is the potential transpiration $\left(\mathrm{mm} \mathrm{day}^{-1}\right)$ and $E_{p}$ is the potential evaporation $\left(\mathrm{mm} \mathrm{day}{ }^{-1}\right)$, which is calculated (Jones, 1985) as follows:

$$
\begin{array}{ll}
E_{p}=E T_{c} \times(1-0.43 L A I) & L A I \leq 1 \\
E_{p}=\frac{E T_{c}}{1.1 e^{-0.4 L A I}} & L A I>1
\end{array}
$$

where, $L A I$ is the leaf area index. The actual plant transpiration $\left(T_{a}\right)$ and actual soil evaporation $\left(E_{a}\right)$ are presented as:

$$
T_{a}=k_{s} \cdot T_{c}, \quad E_{a}=k_{s} \cdot E_{p}
$$

where, $k_{s}$ is the soil water stress coefficient, which is calculated as follows:

$k_{s}=\frac{\ln \left(A_{w}+1\right)}{\ln (101)}, \quad A_{w}=\frac{H-H_{w p}}{H_{f}-H_{w p}}$

where, $H$ is the soil water content, $H_{f}$ is the field capacity, and $H_{w p}$ is the wilting moisture.

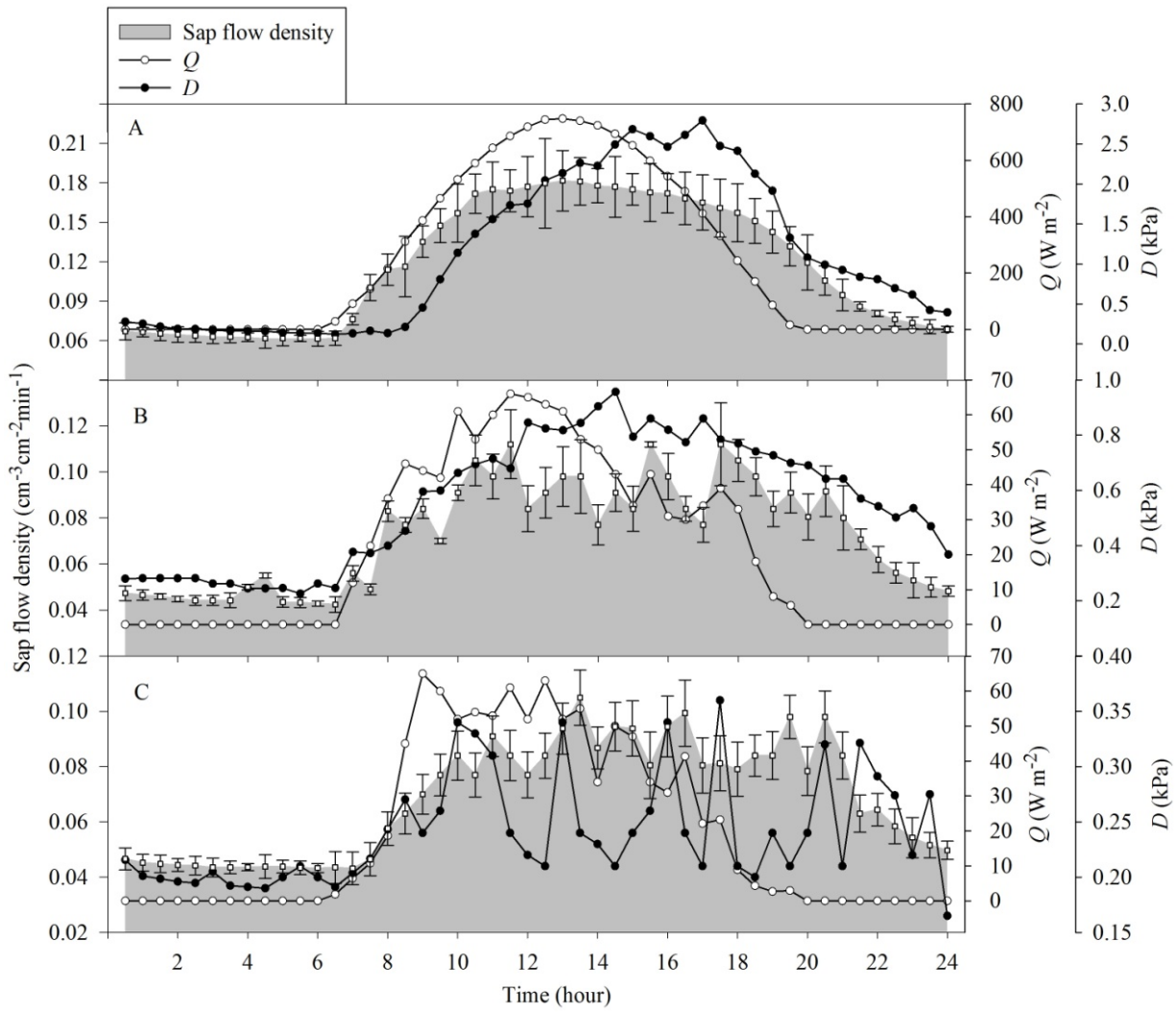

\section{Data analyses}

Stepwise multiple regression analyses were carried out to analyze the relationships between daily changes in stand transpiration and environmental factors (soil water content, photosynthetically active radiation, vapor pressure deficit and potential evapotranspiration). All statistical analyses were conducted with the SPSS software package version 18.0 (IBM, USA). The regression equations were done using SigmaPlot version 11.0 (Systat Software, Chicago, Illinois, USA).

\section{RESULTS}

\section{Diurnal variation of sap flow density}

During the whole growing season, sap flow density in $P$. tabulaeformis had distinct diurnal variation. Three diurnal variation examples of sap flow density in P. tabulaeformis in a sunny day ( $1^{\text {st }}$ June $)$, a cloudy day ( $14^{\text {th }}$ June) and a rainy day ( $18^{\text {th }}$ June) were shown in Fig. 3. Sap flow density was small and relatively steady at night and before dawn under the three weather conditions. Sunny day: sap flow rate increased gradually after 6:30, reached a peak at 13:00, with a value of 0.184 $\mathrm{cm}^{-3} \mathrm{~cm}^{-2} \mathrm{~cm}^{-1}$, then gradually decreased after 14:30, sharply decreased after 18:00, and sap flow was low after 20:30. The results indicated that the sap flow rate in P. tabulaeformis had no significant 'noon-depression' phenomenon. At noon, it is possible that the stomata of $P$. tabulaeformis are not completely closed, so that transpiration continues. Sap flow density on cloudy and rainy days started to increase in the morning about 1 h later than on the sunny day (Fig. 3). In the sunny day, $Q$ and $D$ had the same trend with the daily course of sap flow density, clearly shown by the coincidently high and low values (Fig. $3 \mathrm{~A}$ ), and there was $1-2 \mathrm{~h}$ time lag between sap flow and $D$, but no significant time lag with $Q$. Coefficients of determination $\left(R^{2}\right)$ for the relation of $Q$ and $D$ with sap flow for the three days with different weather conditions (Table 2) show that high $R^{2}$ was found in sunny day, and low $R^{2}$ in rainy day.
Fig. 3. Half-hourly patterns of photosynthetically active radiation $(Q)$, vapour pressure deficit $(D)$ and halfhourly patterns of sap flow density under different weather conditions for $P$. tabulaeformis. A, sunny day $\left(1^{\text {st }}\right.$ June); B, cloudy day (14 $4^{\text {th }}$ June); $\mathrm{C}$, rainy day (18 $8^{\text {th }}$ June). The values of sap flow density represent the mean \pm SD. 
Table 2. Partially adjusted coefficients of determination $R^{2}$ and significance levels $P$ for the relation between transpiration and significant environmental factors between sap flow density and significant environmental factors for days with three contrasting weather conditions. Half-hourly patterns of photosynthetically active radiation $(Q)$, vapour pressure deficit $(D)$.

\begin{tabular}{|c|c|c|c|c|}
\hline \multirow{2}{*}{$\begin{array}{l}\text { Environment } \\
\text { factors }\end{array}$} & \multirow{2}{*}{$\begin{array}{l}\text { Partial coefficient } \\
\text { and significance }\end{array}$} & \multicolumn{3}{|c|}{ Weather conditions } \\
\hline & & $\begin{array}{l}\text { Sunny } \\
\text { day }\end{array}$ & $\begin{array}{l}\text { Cloudy } \\
\text { day }\end{array}$ & $\begin{array}{l}\text { Rainy } \\
\text { day }\end{array}$ \\
\hline \multirow[t]{2}{*}{$Q$} & $R^{2}$ & 0.847 & 0.381 & 0.115 \\
\hline & $P$ & $<0.0001$ & $<0.05$ & 0.16 \\
\hline \multirow[t]{2}{*}{$D$} & $R^{2}$ & 0.816 & 0.324 & 0.109 \\
\hline & $P$ & $<0.0001$ & $<0.05$ & 0.09 \\
\hline
\end{tabular}

\section{Daily variations of stand transpiration}

The observation period was hot, relatively rainy and humid (Figs. 4B and C). The mean daily transpiration of $P$. tabulaeformis was found to be $1.9 \mathrm{~mm} \mathrm{day}^{-1}$, ranging from 0.78 to $2.9 \mathrm{~mm} \mathrm{day}^{-1}$. The mean daily transpiration rates (mean $\left.\pm \mathrm{SD}\right)$ in May, June, July, August and September were 1.8 $\pm 0.2,1.6 \pm 0.3$, $2.2 \pm 0.2,2.1 \pm 0.2$, and $1.3 \pm 0.3 \mathrm{~mm} \mathrm{day}^{-1}$, respectively. Cumulative transpiration determined with the sap flow method of 291.4 $\mathrm{mm}$ amounted to $89 \%$ of total rainfall of this period (Figs. $4 \mathrm{~A}$ and C).

The higher transpiration $\left(E_{c}\right)$ coincided with higher values of daily photosynthetically active radiation $\left(Q_{0}\right)$ and mean daily vapor pressure deficit $\left(D_{z}\right)$ normalized by daylight hours (Figs.
$4 \mathrm{~A}$ and B). Such as on $11^{\text {st }}$ May and $17^{\text {th }}$ June, transpiration rates were 2.21 and $2.45 \mathrm{~mm} \mathrm{day}^{-1}$. Water demand was low as a result of cloudy day. Daily patterns of transpiration of $P$. tabulaeformis showed relatively low values under sunny weather condition from $24^{\text {th }}$ May to $8^{\text {th }}$ June, experienced with 15 days dry period, although $Q_{0}$ remained higher values (Figs. 4A, B and $\mathrm{C}$ ).

\section{Transpiration calculated with Penman-Monteith equation and measured with heat pulse method}

Daily variations in stand transpiration measured with the heat pulse method (E HP) were similar to the transpiration calculated with Penman-Monteith equation (E_PM). E_PM overestimated transpiration by about $16 \%$ for $P$. tabulaeformis in comparison with E_HP (Fig. 5).

\section{Correlation between stand transpiration of $\boldsymbol{P}$. tabulaeformis and the environmental factors}

Volumetric soil water content of the soil layer from 0 to 10 $\mathrm{cm}$ was the highest and changed obviously with rainfall with standard deviation of $5.3 \%$. Soil water contents and variation coefficient in deeper soil layers were relatively low (Fig. 6). Soil water content at $10 \mathrm{~cm}$ depth responded to rain events if the cumulative rainfall over a 3 to 5 days period exceeded 10 to $12 \mathrm{~mm}$. Single rain events of less than $10 \mathrm{~mm}$ had little effect on soil water content at $20 \mathrm{~cm}, 30 \mathrm{~cm}$ and $40 \mathrm{~cm}$ depths (Fig. 6).

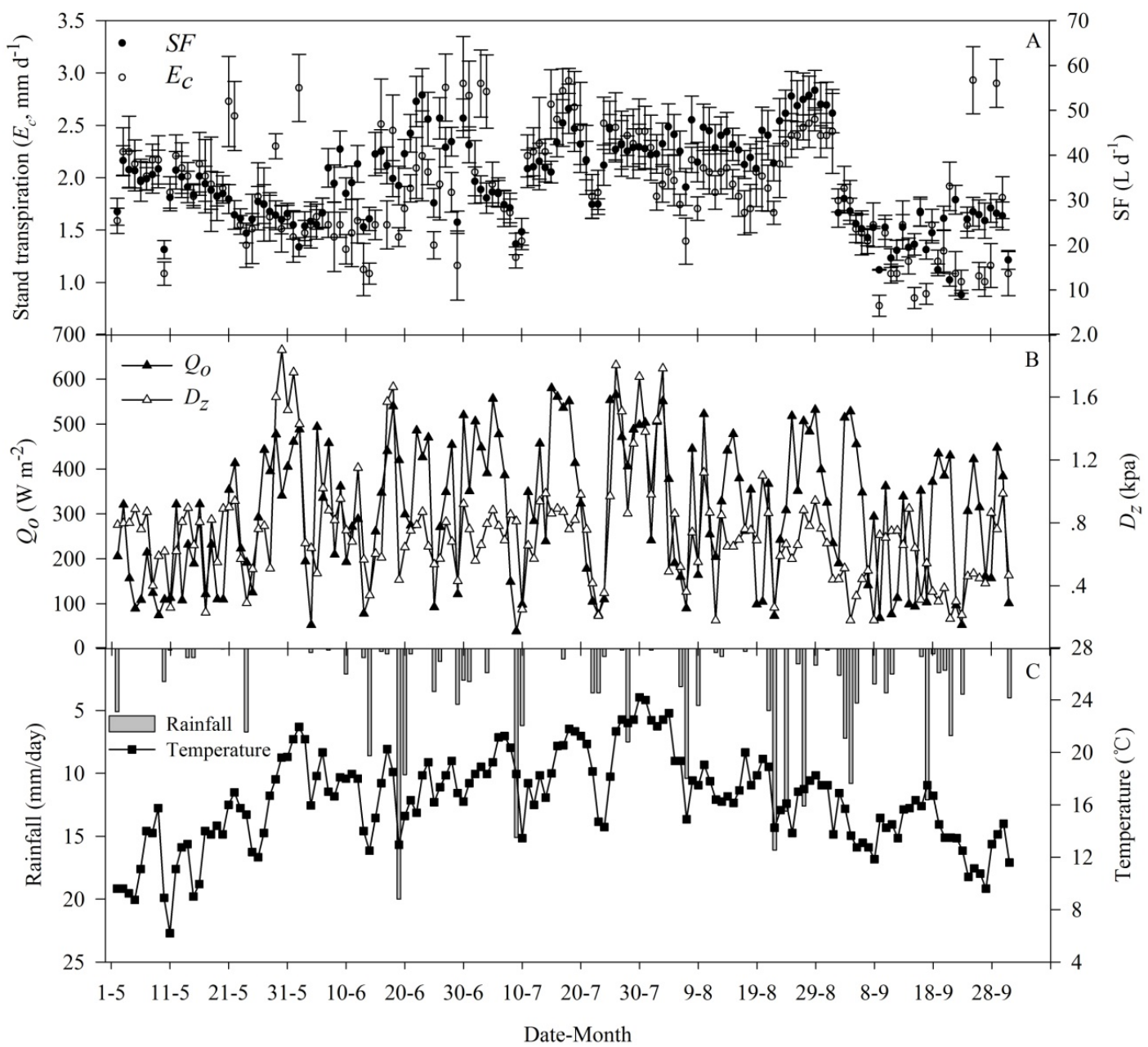

Fig. 4. Daily values for (A) sap flow rate and stand transpiration during the observation period ( $1^{\text {st }}$ May to $30^{\text {th }}$ September), data represent the mean values of the three plots for $P$. tabulaeformis. (B) Daily vapor pressure deficit $\left(D_{z}\right)$ and daily photosynthetically active radiation $\left(Q_{0}\right)$. (C) Temperature and precipitation. The values of $E_{c}$ and $S F$ represent the mean $\pm \mathrm{SD}$. 


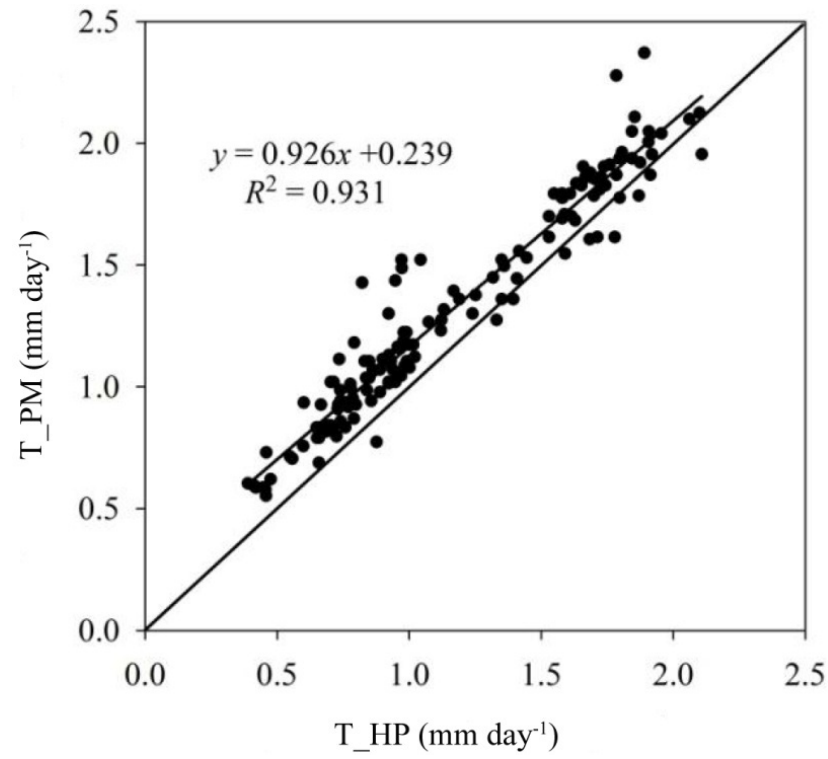

Fig. 5. Comparison between stand transpiration values determined by T_HP (the heat pulse method) and those calculated by T_PM (Penman-Monteith equation) throughout the observed period. Each data point represents a daily mean value.
Coefficients of determination $\left(R^{2}\right)$ of daily vapor pressure deficit $\left(D_{z}\right)$, daily photosynthetically active radiation $\left(Q_{0}\right)$, air temperature $\left(T_{a}\right)$, soil water content $(S W C)$ and potential evapotranspiration $\left(E T_{0}\right)$ versus stand transpiration in each month were presented in Table 3. During the experimental period, daily changes in transpiration correlated with $Q_{0}\left(R^{2}=0.305-\right.$ $0.802)$ and $D_{z}\left(R^{2}=0.311-0.824\right)$, however, in May the lowest values of $R^{2}$ were found. Meanwhile, $S W C$ had the highest values of $R^{2}$ in May.

The multiple linear regression of the stand transpiration in each month of $P$. tabulaeformis with the $S W C, D_{z}, Q_{\mathrm{o}}, T_{a}$, and $E T_{0}$ was presented in Table 4 . The stand transpiration in $P$. tabulaeformis was correlated to $D_{z}, Q_{0}$ and $T_{a}$ in August. The $S W C$ was the only factor affecting the stand transpiration in May. But the stand transpiration was related to $D_{z}$ and $Q_{0}$ in other months.

To elucidate response patterns of transpiration to environmental factors, daily mean transpiration was correlated with $Q_{\mathrm{o}}$ and $D_{z}$ conditions obtained at the study site $2 \mathrm{~m}$ above ground. Total transpiration increased sharply with $D_{z}$ at low levels $\left(D_{z}<0.9 \mathrm{kPa}\right)$, but tended to level off at higher $D_{z}$ values (Fig. 7a). The data increases in $Q_{0}$ up to values of $0-500 \mathrm{~W} \mathrm{~m}^{-2}$ produced a reasonably linear increase in transpiration, after which transpiration tended to level off for higher values of $Q_{0}$ (Fig. 7b).

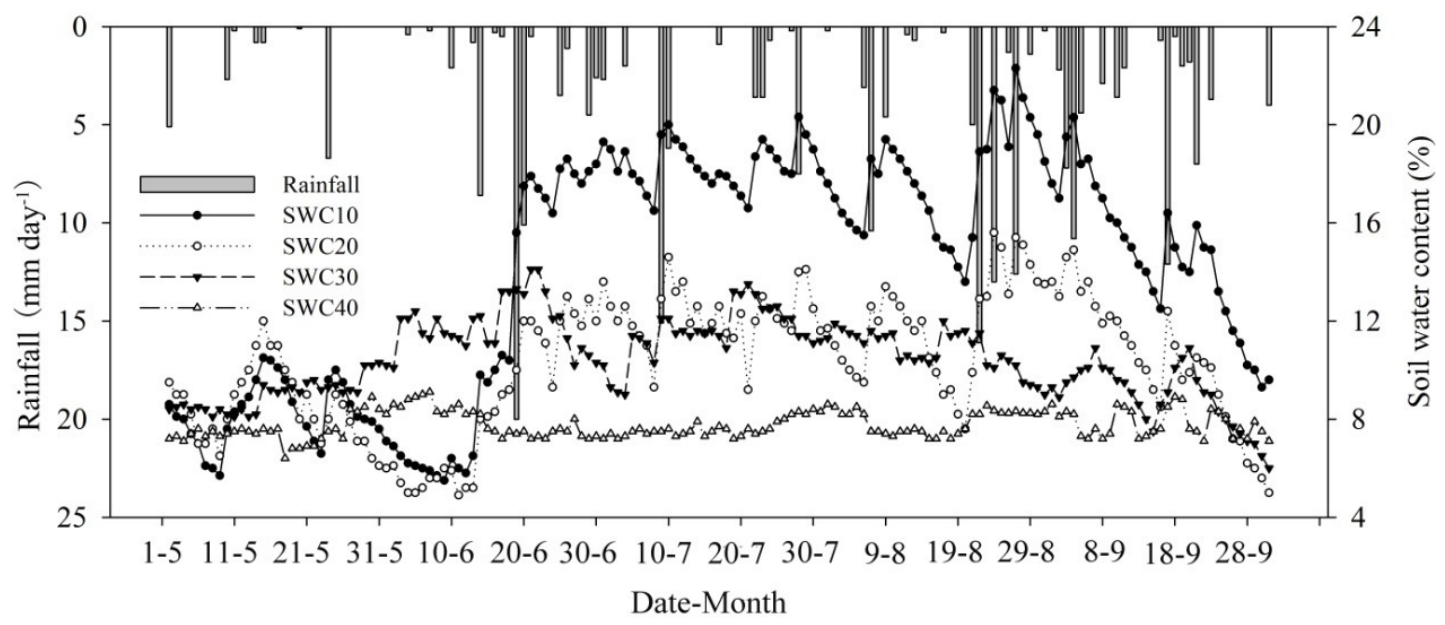

Fig. 6. The dynamic variation of rainfall events and volumetric soil water contents in $10 \mathrm{~cm}$ (SWC10), $20 \mathrm{~cm}$ (SWC20), $30 \mathrm{~cm}$ (SWC30), and $40 \mathrm{~cm}(\mathrm{SWC} 40)$ below the soil surface.
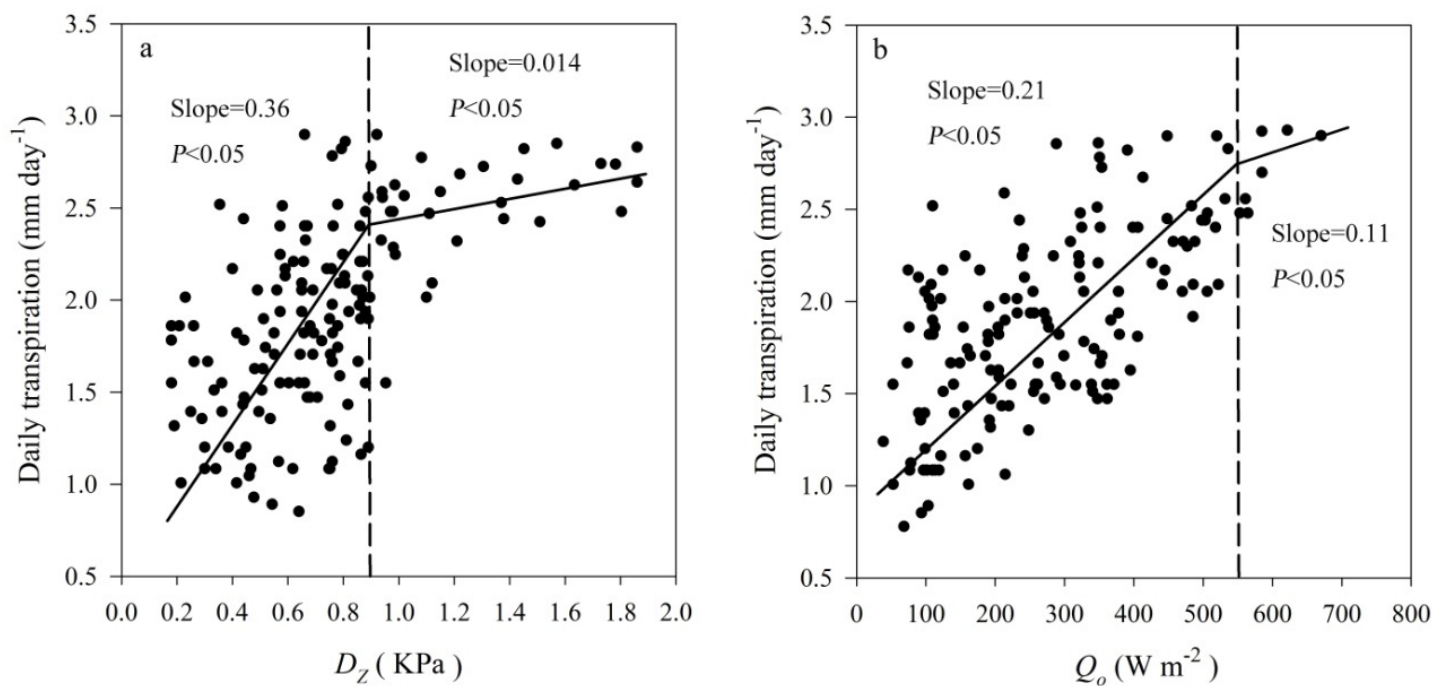

Fig. 7. The relationships between daily mean transpiration rate and daily vapor pressure deficit $\left(D_{z}\right)$ and daily photosynthetically active radiation $\left(Q_{0}\right)$. 
Table 3. Partially adjusted coefficients of determination $R^{2}$ and significance levels $P$ for the relation between transpiration and significant environmental factors such as daily vapor pressure deficit $\left(D_{z}\right)$, daily photosynthetically active radiation $\left(Q_{0}\right)$, air temperature $\left(T_{a}\right)$, soil water content $(S W C)$, and potential evapotranspiration $\left(E T_{0}\right)$, for May, June, July, August, and September 2014; the number of values is $n=$ 153.

\begin{tabular}{lllllll}
\hline Environment factors & Partial coefficient & Month & & & \\
\cline { 2 - 6 } & and significance & May & June & July & August & September \\
\hline$Q_{0}$ & $R^{2}$ & 0.305 & 0.765 & 0.783 & 0.802 & 0.711 \\
& $P$ & $<0.05$ & $<0.0001$ & $<0.0001$ & $<0.0001$ & $<0.0001$ \\
$D_{z}$ & $R^{2}$ & 0.311 & 0.824 & 0.694 & 0.733 & 0.795 \\
& $P$ & $<0.05$ & $<0.0001$ & $<0.0001$ & $<0.0001$ & $<0.0001$ \\
$T_{a}$ & $R^{2}$ & 0.502 & 0.514 & 0.465 & 0.672 & 0.582 \\
$S W C$ & $P$ & $<0.01$ & $<0.01$ & $<0.01$ & $<0.01$ & $<0.01$ \\
& $R^{2}$ & 0.802 & 0.505 & 0.306 & 0.415 & 0.426 \\
$E T_{0}$ & $P$ & $<0.0001$ & $<0.01$ & $<0.01$ & $<0.01$ & $<0.01$ \\
& $R^{2}$ & 0.311 & 0.206 & 0.453 & 0.336 & 0.240 \\
\end{tabular}

Table 4. The multiple linear correlation equations between daily stand transpiration $\left(E_{c}\right)$, and environmental factors for individual months during the observation period ( $\left(1^{\text {st }}\right.$ May $-30^{\text {th }}$ September 2014) for $P$. tabulaeformis; $n$ is number of values (days); the independent variables are daily vapor pressure deficit $\left(D_{z}\right)$, daily photosynthetically active radiation $\left(Q_{0}\right)$, daily mean air temperature $\left(T_{a}\right)$, soil water content $(S W C)$ and potential evapotranspiration $\left(E T_{0}\right)$.

\begin{tabular}{lllll}
\hline Month & Regression equations & $R^{2}$ & $F$ & $n$ \\
\hline May & $E_{c}=0.986+0.197 S W C$ & $0.756^{*}$ & 49.866 & 31 \\
June & $E_{c}=2.034+0.502 D_{z}+1.345 \times 10^{-3} Q_{o}$ & $0.806^{*}$ & 60.234 & 30 \\
July & $E_{c}=2.037+0.366 D_{z}+1.215 \times 10^{-3} Q_{o}$ & $0.824^{*}$ & 55.122 & 31 \\
August & $E_{c}=3.345+0.157 D_{z}+1.005 \times 10^{-3} Q_{o}-8.64 \times 10^{-2} T_{a}$ & $0.836^{*}$ & 50.475 & 31 \\
September & $E_{c}=1.976+0.119 D_{z}+2.034 \times 10^{-3} Q_{o}$ & $0.791^{*}$ & 63.120 & 30 \\
\hline
\end{tabular}

*indicates significant difference $(P<0.05)$.

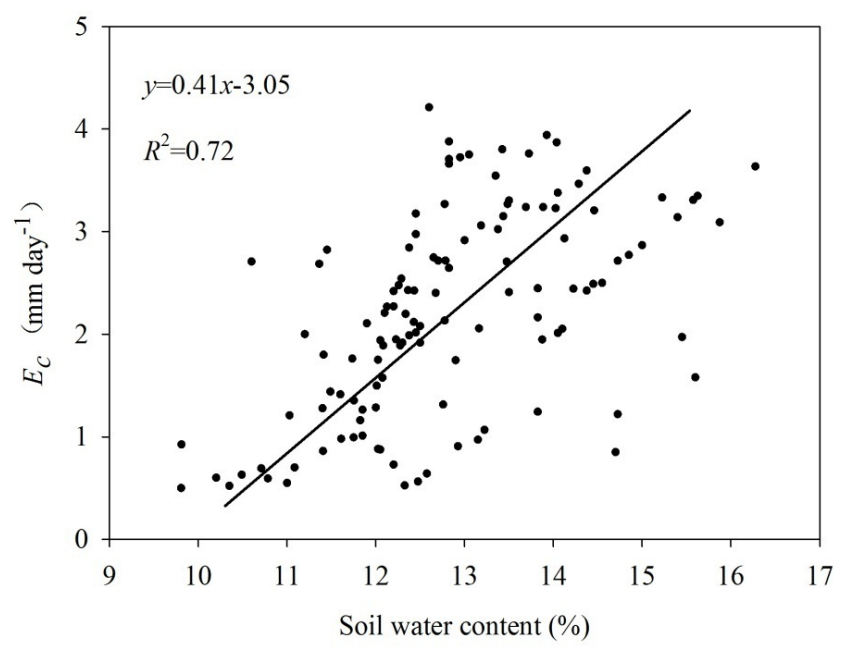

Fig. 8. Changes in $E_{c}$ in response to changes in soil moisture at 0-40 $\mathrm{cm}$ below the soil surface. Curves represent the results of linear regression

The results revealed that the variation in sap velocity could be expressed as a linear function of soil moisture (Fig. 8), and the regression equation had a high coefficient of determination $\left(R^{2}\right)$.

\section{DISCUSSION \\ Comparison between $P$. tabulaeformis transpiration and total evaporation}

Our results showed an underestimation of transpiration determined by the sap flow method, as compared with the Penman-Monteith equation That was in contradiction to those of authors who conclude that the extrapolation of stem-level flows to the transpiration of a canopy often produces a systematic overestimation of transpiration (Duniway et al.,
2010; Ma et al., 2001; Wang et al., 2009). The steady-state assumption of a constant proportionality between sap flow rates and leaf area for all stems is generally advanced to explain this overestimation. The small discrepancy between sap flow method and Penman-Monteith equation might be due to two different factors in our case. First, the calculated $P$. tabulaeformis transpiration rate was assumed to be nearly equal to the sum of the transpiration from all sunlit leaves, and the majority of leaves were assumed to be sunlit. However, a more accurate value of total leaf area of a $P$. tabulaeformis might be slightly greater than that obtained from the field, though there were no experimental data to confirm this in the present study. The second possible source of error may be that the contribution of evaporation from the soil surface in the Penman-Monteith equation is not taken into account by the sap flow method. Subtracting soil evaporation from total evaporation, Fig. 5 could give acceptable results with daily differences of less than $16 \%$ between the sap flow method extrapolated to whole $P$. tabulaeformis and Penman-Monteith equation, suggesting that sap flow measurements can be used to provide reliable estimates of stand transpiration in the study area.

\section{Transpiration variation}

In previous studies, sap flow was measured by heat pulse method in similar environmental condition; sap flow of individual longleaf pine was $2-142 \mathrm{~L} \mathrm{~d}^{-1}$ (Bosch et al., 2014) and the stand-level transpiration of Norway spruce was $1.4-2.8 \mathrm{~mm}$ $\mathrm{d}^{-1}$ (Alsheimer et al., 1998). These values agreed closely with those obtained for P. tabulaeformis in the current study $(9-56 \mathrm{~L}$ $\left.\mathrm{d}^{-1}\right)$. In the whole growing season, the sap woodarea of P. tabulaeformis varied regularly from day to night, especially on sunny days (Fig. 3). Giorio and Giorio (2003) also reported that the variation of sap flow for olive tree in the sunny days was greater than in the cloudy days. Xiong et al. (2003) pointed out 
that the sap flow of Larix principis-rupprechtii, which was one of the most principal species for afforestation in northwest China, changes regularly from day to night in later growth season in both typical sunny and cloudy days, but the sap flow rate in the sunny days was greater than that of the cloudy days. In the night, the sap flow rate was slow and rapidly increased with the solar radiation and air temperature in the morning. Yan et al. (1999) reported that Juglans mandshurica had several peaks during a single day of sap flow rate, and sap flow continued during night, but sap flow rate was much lower and maintained constant. Sun et al. (2002) also indicated that night sap flow rate of Betula platyphylla was only $11-40 \%$ of that of the day and the variation of sap flow rate in sunny days was greater than that of cloudy days. In the current study, sap flow rates in different weather conditions had different influence factors. The diurnal and seasonal variations of sap flow rate in $P$. tabulaeformis under different weather conditions were in agreement with the previous studies.

Although $P$. tabulaeformis is regarded as a tree species of potentially high water consumption in the region, in our research, however, total stand transpiration of the P. tabulaeformis plantation (about 40 years) was $291.4 \mathrm{~mm}$ during the growing season of 2014 and related to environmental factors. The relatively small estimates of stand transpiration can be attributed to the low sap wood area of the stand. However, considering the relatively low $P$. tabulaeformis and the age of the plantation, questions are arising about whether the stand transpiration of the young growth of $P$. tabulaeformis in the same region is higher, and how much stands of corresponding ages in a valley site transpire. These issues should be considered carefully when assessing and analyzing long-term water budgets of $P$. tabulaeform is plantations in relation to their growth and sustainability in the region.

\section{The response of sap flow to environmental factors}

Zhang et al. (2009) indicated that $D_{z}$ and solar radiation affected the stand transpiration of apple trees (Malus domestica Borkh.) greatly and the sap flow rate increased with the $D_{z}$ and solar radiation in the sunny days (Xiong et al., 2003). The average daily stand transpiration of two eucalyptus (Eucalyptus urophylla $\mathrm{S}$. T. Blake) plantations was significantly related to available soil water content and daily $D_{z}$ (Yin et al., 2003). In the experiment presented in this article, the trunk sap flow rate in $P$. tabulaeformis was found as the function of the $D_{z}$ and $Q_{0}$, but the two environmental factors affecting the sap flow rate varied in each month. An another study in northeast China showed that air temperature, relative humidity, and $Q_{0}$ were also the major three factors affecting sap flow rate of Betula platyphylla on clear days, but the importance of the three factors was varied in different growth stages (Sun et al., 2002).

The soil surface was often considered as a source of water vapor as important as plant leaves (Rodríguez-Caballero et al., 2012). The transpiration response of $P$. tabulaeformis to greater water use was shown to exhibit low $R^{2}$ values with increasing $Q_{0}$ and $D_{z}$ (Table 3), indicating that $Q_{0}$ and $D_{z}$ were not the single influenced factors, considering the low rainfall of 16.4 $\mathrm{mm}$ in May (Fig. 4C).

Transpiration was frequently restricted by soil water availability in the upper soil profile, but $P$. tabulaeformis could still meet their water demand. The transpiration rates maintained high values, despite high temperature and intense radiation on representative clear days for P. tabulaeformis (Figs. 4A and B). This was due to the deeper, more developed rooting systems. Our previous study had reported that the root distribution pat- terns of $P$. tabulaeformis in the same area (Jian et al., 2014). The roots of $P$. tabulaeformis can reach as deep as $2.8 \mathrm{~m}$. The majority of uptake roots were concentrated in the upper $1.0 \mathrm{~m}$ of soil (Liu et al., 2012). Root water uptake from deeper soil layer, transported to the upper soil layer at night. This phenomenon was very important in arid and semi-arid area, which can make the plants maintain the transpiration (Gao et al., 2011).

\section{CONCLUSIONS}

Because of insufficient water availability in the semiarid region of Loess Plateau, accurate estimation of water consumption by a forest stand is crucial for understanding water-use characteristics. Use of the sap flow method enabled us to quantify forest stand transpiration in this loess hill and gullied area, because stand transpiration can be estimated by monitoring the sap flow in stems without consideration of ground unevenness and topographical heterogeneity. Further studies, including investigations of transpiration of $P$. tabulaeformis with different age classes and of understory vegetation, evaporation of soil and tree canopies, and other water flow elements in stand, for example runoff, are required to resolve these uncertainties.

Acknowledgement. This project was supported by National Key Research Priorities Program of China (2016YFC0402402); National Natural Science Foundation of China (31700370); The Special Research Fund of Yellow River Institute of Hydrau lic Research (HKY-JBYW-2018-10); Drought Meteorological Science Research fund (IAM201705); National Natural Science Foundation of China (51409116); Startup Research Fund of Zhengzhou University (1512323001); Institution of higher learning key scientific research project, Henan Province (16A570010); China postdoctoral science foundation (2016M602255); Henan province postdoctoral science foundation.

\section{REFERENCES}

Allen, R.G., Pereira, L.S., Reas, D., Smith, M., 1998. Crop evapotranspiration guidelines for computing crop water requirements. FAO Irigation and Drainage Paper 56. Food and Agriculture Organization of the United Nations, Rome, Italy.

Alsheimer, M., Köstner, B., Falge, E., Tenhunen, J.D., 1998. Temporal and spatial variation in transpiration of Norway spruce stands within a forested catchment of the Fichtelgebirge, Germany. Ann. For. Sci., 55, 103-124.

Bai, Y., Wang, Y., 2011. Spatial variability of soil chemical properties in a Jujube slope on the Loess Plateau of China. Soil Sci., 176, 10, $550-558$.

Blackman, C.J., Brodribb, T.J., 2011. Two measures of leaf capacitance: insights into the water transport pathway and hydraulic conductance in leaves. Funct. Plant Biol., 38, 2, 118-126.

Bosch, D.D., Marshall, L.K., Teskey, R., 2014. Forest transpiration from sap flux density measurements in a Southeastern Coastal Plain riparian buffer system. Agric. For. Meteorol., 187, 72-82.

Cao, L., Zhang, K., and Zhang, W. 2009. Detachment of road surface soil by flowing water. Catena, 76, 2, 155-162.

Cao, C.Y., Jiang, S.Y., Zhang, Y., Zhang, F.X., Han, X.S., 2011. Spatial variability of soil nutrients and microbiological properties after the establishment of leguminous shrub Caragana microphylla Lam. Plantation on sand dune in the Horqin Sandy Land of Northeast China. Ecol. Eng., 37, 10, 1467-1475.

Čermák, J., Cienciala, E., Kučera, J., 1995. Individual variation of sapflow rate inlarge pine and spruce trees and stand transpiration: a pilot study at the central. J. Hydrol., 168, 109-120.

Chazdon, R.L., 2008. Beyond deforestation: restoring forests and ecosystem services on degraded lands. Science, 320, 5882, 14581460 . 
Chen, H.S., Shao, M.A., Li, Y.Y., 2008. Soil desiccation in the Loess Plateau of China. Geoderma, 143, 1-2, 91-100.

Cortina, J., Amat, B., Castillo, V., Fuentes, D., Maestre, F.T., Padilla, F., Rojo, L., 2011. The restoration of vegetation cover in the Iberian southeast. J. Arid Environ., 75, 12, 1377-1384.

Du, S., Wang, Y.L., Kume, T., Zhang, J.G., Otsuki, K. Yamanaka, N., Liu, G.B., 2011. Sapflow characteristics and climatic responses in three forest species in thesemiarid Loess Plateau region of China. Agric. For. Meteorol., 151, 1-10.

Duniway, M.C., Snyder, K.A., Herrick, J.E., 2010. Spatial and temporal patterns of water availability in a grass-shrub ecotone and implications for grassland recovery in arid environments. Ecohydrology, 3, 1, 55-67.

Derak, M., Cortina, J., 2014. Multi-criteria participative evaluation of Pinus halepensis plantations in a semiarid area of southeast Spain. Ecol. Indic., 43, 8, 56-58.

Edwards, W.R.N., Booker, R.E., 1984. Radial variation in the axial conductivity of Populus and its significance in heat pulse velocity measurement. J. Exp. Bot., 35, 551-561.

Fu, W., Huang, M., Gallichand, J., Shao, M.A., 2012. Optimization of plant coverage in relation to water balance in the Loess Plateau of China. Geoderma, 173, 134-144.

Gao, X., Wu, P., Zhao, X., Shi, Y., Wang, J., 2011. Estimating spatial mean soil water contents of sloping jujube orchards using temporal stability. Agric. Water Manage., 102, 1, 66-73.

Giorio, P., Giorio, G., 2003. Sap flow of several olive trees estimated with the heat-pulse technique by continuous monitoring of a single gauge. J. Exp. Bot., 49, 9-20.

Granier, A., 1987. Evaluation of transpiration in a Douglas-fir stand by means of sap flow measurements. Tree Physiol., 3, 309-319.

Huang, M.B., Barbour, S.L., Si, B.C., Elshorbagy, A., Zettl, J., 2011. Infiltration and drainage processes in multi-layered coarse soils. Can. J. Soil Sci., 91, 2, 169-183.

Han, L. X., Wang, Y. K., Li, X. B., Zhang, P., 2012. Improved irrigation scheduling for pear-jujube trees based on trunk diameter sensing data. Afr. J. Biotech., 11, 7, 1597-1606.

Issa, O.M., Valentin, C., Rajot, J.L., Cerdan, O., Desprats, J.F., Bouchet, T., 2011. Runoff generation fostered by physical and biological crusts in semi-arid sandy soils. Geoderma, 167-168, 1, 22-29.

Jiao, F., Wen, Z.M., An, S.S., 2011. Changes in soil properties across a chronosequence of vegetation restoration on the Loess Plateau of China. Catena, 86, 2, 110-116.

Jiao, L., Lu, N., Sun, G., Ward, E.J., Fu, B.J., 2016. Biophysical controls on canopy transpiration in a black locust (Robinia pseudoacacia) plantation on the semi-arid Loess Plateau, China. Ecohydrology, 9, 1068-1081.

Jian, S.Q., Zhao, C.Y., Fang, S.M., Yu, K., 2015. The distribution of fine root length density for six artificial afforestation tree species in Loess Plateau of Northwest China. Forest Sys., 43, 1, 1-9.

Jones, C., 1985. CERES-Maize: a stimulation model of maize growth and development. NTIS, Springfield, Virginia, USA.

Liu, J.G., Li, S.X., Ouyang, Z.Y., Tam, C., Chen, X.D., 2008. Ecological and socioeconomic effects of China's policies for ecosystem services. Proc. Natl. Acad. Sci. USA 105, 28, 9477-9482.

Liu, W.Z., Zhang, X.C., Dang, T.H., Ouyang, Z., Li, Z., Wang, J., Wang, R., Gao, C.Q., 2010. Soil water dynamics and deep soil recharge in a record wet year in the southern Loess Plateau of China. Agric. Water Manage., 97, 8, 1133-1138.

Liu, C., Du, T., Li, F., Kang, S., Li, S., Tong, L., 2012. Trunk sap flow characteristics during two growth stages of apple tree and its relationships with affecting factors in an arid region of northwest China. Agric. Water Manage., 104, 2, 193-202.

Ma, L.Y., Sun, P.S., Ma, L.Y., 2001. Sapwood area calculation and water use scaling up from individual trees to stands of Chinese pine and black locust. Journal of Beijing Forestry University, 23, 4, 1-5 (In Chinese with English abstract).

Ma, L.H., Wu, P.T., Wang, Y.K., 2012. Spatial distribution of roots in a dense jujube plantation in the semiarid hilly region of the Chinese Loess Plateau. Plant Soil, 354, 1-2, 57-68.

Malagnoux, M., 2007. Arid Land Forests of the World: Global Environmental Perspectives. FAO, Rome.
Moran, M.S., Scott, R.L., Keefer, T.O., Emmerich, W.E., Hernandez, M., Nearing, G.S., Paige, G.B., Cosh, M.H., O'Neill, P.E., 2009. Partitioning evapotranspiration in semiarid grassland and shrubland ecosystems using time series of soil surface temperature. Agric. For. Meteorol., 149, 1, 59-72.

Rodríguez-Caballero, E., Cantón, Y., Chamizo, S., Afana, A., SoléBenet, A., 2012. Effects of biological soil crusts on surface roughness and implications for runoff and erosion. Geomorphology, 145146, 4, 81-89.

Sun, H.Z., Zhou, X.F., Zhao, H.X., 2002. A research on stem sap flow dynamic of Betula platyphylla. Acta Ecologica Sinica, 22, 9, $1387-$ 1391.

Swanson, R.H., Whitfield, D.W.A., 1981. A numerical analysis of heat pulse velocity theory and practice. J. Exp. Bot., 32, 1, 221-239.

Wang, X.L., Sun, G.J., Jia, Y., Li, F.M., Xu, J.Z., 2008. Crop yield and soil water restoration on 9-year-old alfalfa pasture in the semiarid Loess Plateau of China. Agric. Water Manage., 95, 3, 190-198.

Wang, Y.Q., Fan, J., Shao, M.A., 2009. Evapotranspiration of three types of plants in water-wind erosion crisscross regions in the Loess Plateau. Acta Ecol. Sin., 29, 10, 5386-5394. (In Chinese with English abstract).

Wang, Y.Q., Shao, M.A., Shao, H.B., 2010. A preliminary investigation of the dynamic characteristics of dried soil layers on the Loess Plateau of China. J. Hydrol., 381, 1-2, 9-17.

Wang, Y.Q., Shao, M.A., Zhu, Y.J., Liu, Z.P., 2011. Impacts of land use and plant characteristics on dried soil layers in different climatic regions on the Loess Plateau of China. Agric. For. Meteorol., 151, $4,437-448$.

Wang, B., Zhang, G.H., Shi, Y.Y., Zhang, X.C., 2013. Effect of natural restoration time of abandoned farmland on soil detachment by overland flow in the Loess Plateau of China. Earth Surf. Proc. Land., 38, $14,1725-1734$.

Xiao, B., Wang, Q., Zhao, Y., Shao, M., 2011. Artificial culture of biological soil crusts and its effects on overland flow and infiltration under simulated rainfall. Appl. Soil Ecol., 48, 1, 11-17.

Xiong, W., Wang, Y.H., Xu, D.Y., 2003. Regulation of water use for transpiration of Larix Principi-Rupprechtii plantation and its response on environmental factors in southern Ningxia Hilly area. Scientia Silvae Sinicae, 39, 2, 1-7.

Yan, C.R., Downey, A., Han, X.G., Chen, L.Z., 1999. A study on sap flow Juglans mandshurica of growth season in deciduous broadleaf forest Beijing mountain area. Acta Ecologica Sinica, 37, 6, 793-797.

Yaseef, N.R., Yakir, D.E., Rotenberg, S.G., Cohen, S., 2009. Ecohydrology of a semi-arid forest: partitioning among water balance components and its implications for predicted precipitation changes. Ecohydrology, 3, 2, 143-154.

Yin, G.C., Zhou, G.Y., Wang, X., Chu, G.W., Huang, Z.H., 2003. A study on sap flow rate density of two eucalyptus (Eucalyptus ueophylla) plantation in southeastern China by heat-pulse method. Acta Ecologica Sinica, 23, 10, 1984-1990.

Zhang, G.H., Tang, M.K., Zhang, X.C., 2009. Temporal variation in soil detachment under different land uses in the Loess Plateau of China. Earth Surf. Proc. Land., 34, 9, 1302-1309.

Zhang, P., Wang, Y.K., Zhan, J.W., Wang, X., Peng, W., 2010. Scheduling irrigation for jujube (Ziziphus jujuba Mill.). Afr. J. Biotech., $35,5694-5703$.

Zhang, J.G., Guan, J.H., Shi, W.Y., Yamanaka, N., Du, S., 2015. Inter annual variation in stand transpiration estimated by sap flow measurement in a semi-arid black locust plantation, Loess Plateau, China. Ecohydrology, 8, 137-147.

Zhao, Y., Peth, S., Hallett, P., Wang, X.Y., Giese, M., Gao, Y.Z., Horn, R., 2011. Factors controlling the spatial patterns of soil moisture in a grazed semi-arid steppe investigated by multivariate geostatistics. Ecohydrology, 4, 1, 36-48.

Zuo, Q.T., Hu, D.S., Dou, M., Zhang, X., Ma, J.X., 2014. Framework and Core System of the Most Stringent Water Resource Management System Based on the Concept of Human-Water Harmony. Resour. Sci., 36, 5, 906-912. (In Chinese with English abstract)

Received 6 July 2017 Accepted 12 June 2018 